\title{
lonospheric longitudinal variability in the Northern Hemisphere during magnetic storm from the GPS/GLONASS data
}

\author{
M. A. Chernigovskaya, B. G. Shpynev, A. S. Yasyukevich, D. S. Khabituev \\ Institute of Solar-Terrestrial Physics SB RAS, Irkutsk, 664033, Russia \\ E-mail: cher@iszf.irk.ru
}

\begin{abstract}
Longitudinal-temporal variations of the ionization of the mid- and high latitude ionosphere in the Northern Hemisphere are analysed based on the data of the chains of GPS/ GLONASS dual frequency phase receivers during the strongest magnetic storms of the current 24 solar activity cycle - in March and June 2015. The observed ionospheric effects exhibit pronounced longitudinal inhomogeneity associated with the presence of longitudinal features background structure and variations of the geomagnetic field. During the recovery storm phase, important role in dynamics of the mid-latitude ionosphere may belong to disturbances in the form of thermospheric waves of molecular gas propagating westward for several days.
\end{abstract}

Accepted: 15.09 .2020

DOI: 10.21046/2070-7401-2020-17-6-145-152

\section{Introduction}

This article presents an experimental study of spatial and temporal variations of the ionization of the mid- and high latitude ionosphere in the Northern Hemisphere during geomagnetic storms associated with disturbances in the Earth's magnetosphere, which are primarily determined by solar activity [1-3]. Investigation of the geomagnetic storm effects on the Earth upper atmosphere is an important part of the space weather study. Our current understanding of ionospheric storms is based on more than sixty-year data of ground-based observations and on the new possibilities provided by satellitebased techniques. Storm effects derived from the ground-based observations were classified in details in review [4], where the role of various factors was discussed: propagation of storm effects in latitude and longitude, penetration of electric fields from high to low latitudes, enhancements of the equatorward wind and dusk enhancement in electron density at mid-latitudes [5-7]. Application of the GPS/ GLONASS receiver technique for ionospheric study increases significantly the possibility for global storm effect investigation. The sounding technique with signals of GPS/GLONASS allows continuous information on variations in total electron content (TEC) that reflects the plasma conditions throughout the ionosphere. Using the GPS/GLONASS receiver technique together with the global circulation models provides the important way to predict ionosphere storm effects [8-12]. Models and observations complement each other and both are essential for improved understanding of storm phenomena and their effects.

Typically, in storm studies the main attention is paid to the propagation of storm effects from high to low latitudes; it is accomplished by the changes in geomagnetic field structure and by movement of auroral oval equatorward. Longitudinal variations were considered usually relatively to the local time of the ionospheric observation region. This consideration allows revealing such well known effects as dusk enhancement or nighttime depletion [4]. 
In this paper we consider the response of the ionosphere system during the two strongest geomagnetic storms of the current 24 solar activity cycle - in March and June 2015. These events have broadly been studied by different scientific groups [13-26]. Most of these studies used GPS or Low Elevation Orbit (LEO) system together with GPS data. For the storm analysis, they also used longitudinal ionosonde chains in the Asian, African and American sectors [27, 28].

The first research of the ionosphere response to the March 2015 severe geomagnetic storm according to Eurasian mid-latitude ionosonde chain data showed the longitudinal irregularity of the ionosphere over Eurasia [26]. Unfortunately, the mid-latitude ionosonde chain covers only the Eurasian continent in the Eastern Hemisphere. There are no ionosondes in the Western Hemisphere in this mid-latitudes range of the North American continent. For complete study of longitudinal variations along the entire circle of latitude in the mid- and high-latitude ionosphere of the Northern Hemisphere both in the Eastern and Western Hemispheres during severe geomagnetic storms, in present study we analysed data from the chains of GPS/GLONASS dual-frequency phase receivers.

\section{Experimental data and analysis results}

To study longitudinal variations along the entire latitude circle in the mid- and high-latitude ionosphere of the Northern Hemisphere, in present analysis were used data from two chains of GPS/ GLONASS dual-frequency phase receivers. GPS/GLONASS receivers are located along the mainland and on the islands along the entire latitude circle of $60-70^{\circ}$ and $50-55^{\circ} \mathrm{N}$ (figure 1a). Vertical vTEC from initial series was calculated based on the modelled absolute TEC, considering the differential code delays [29].
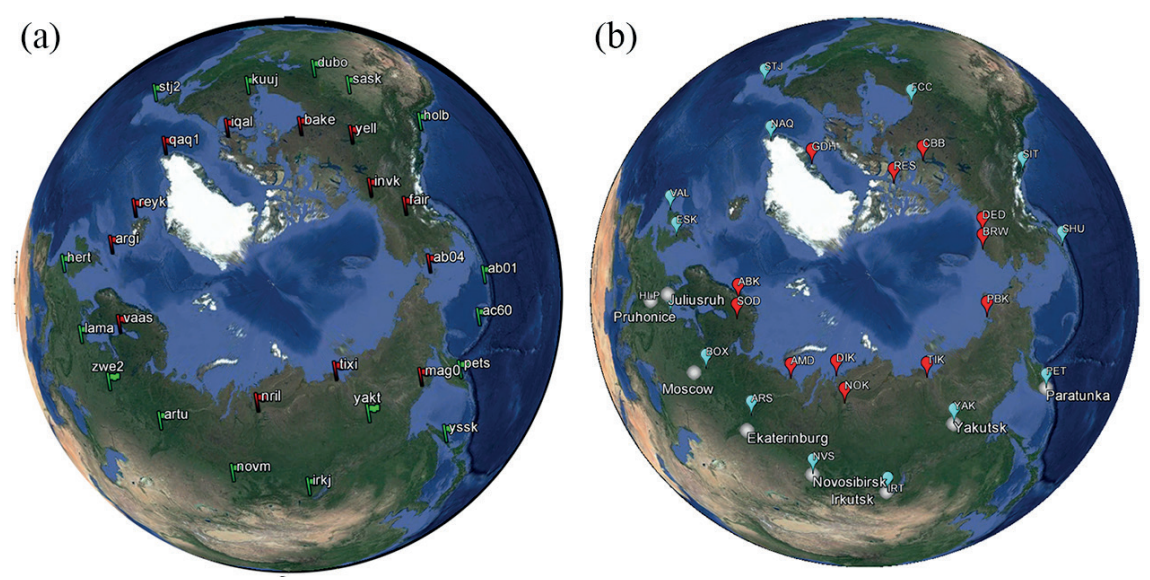

Figure 1. Chain locations: GPS/GLONASSS receivers (a), ionosondes (white circles) and magnetometers [26] (b)

Both magnetic storms were severe according storm classification based on the $D_{s t}$ planetary index [30]. According to NASA classification, the storms were classified as G4.

In March 2015, a magnetic storm began on March 17 (named the St. Patrick's Day storm, after the day of commencement). According to information posted at (www.solen.info/solar/old_reports/), which is based on data from the SOHO satellite, the storm resulted from the interaction of the Earth's magnetosphere and high-velocity solar wind flows from 4 coronal holes and coronal mass ejection following a relatively weak C9.1 X-ray flare registered on 15 March 2015. The main storm phase lasted $\sim 16.5$ hours from 06:23 to 22:47 UT on 17 March 2015. In the storm maximum, the $D_{s t}$-index dropped to $-223 \mathrm{nT}$ (figure 2a); $K_{p}$-index increased from $5^{+}$to $8^{-} ; A_{p}$-index reached 179 .

The second most intense magnetic storm in the current cycle of solar activity resulted from interaction of the Earth's magnetosphere and the high-velocity solar wind flows, coronal mass ejections and M6.5 solar flare at 18:23 UT on 22 June 2015 (www.solen.info/solar/old_reports/). Fronts of 3 interplanetary shock waves of different intensity came to the Earth from 21 to 23 June 2015. The front of the third, strongest shock wave reached the Earth's magnetosphere at 18:30 UT on 22 June, after which a G4 geomagnetic storm began and lasted for many hours. In the storm maximum, the $D_{s t}$-index decreased to $-204 \mathrm{nT}$ (figure $2 \mathrm{~b}$ ), $K_{p}$-index increased to $8^{+}, A_{p}$ reached 236. 

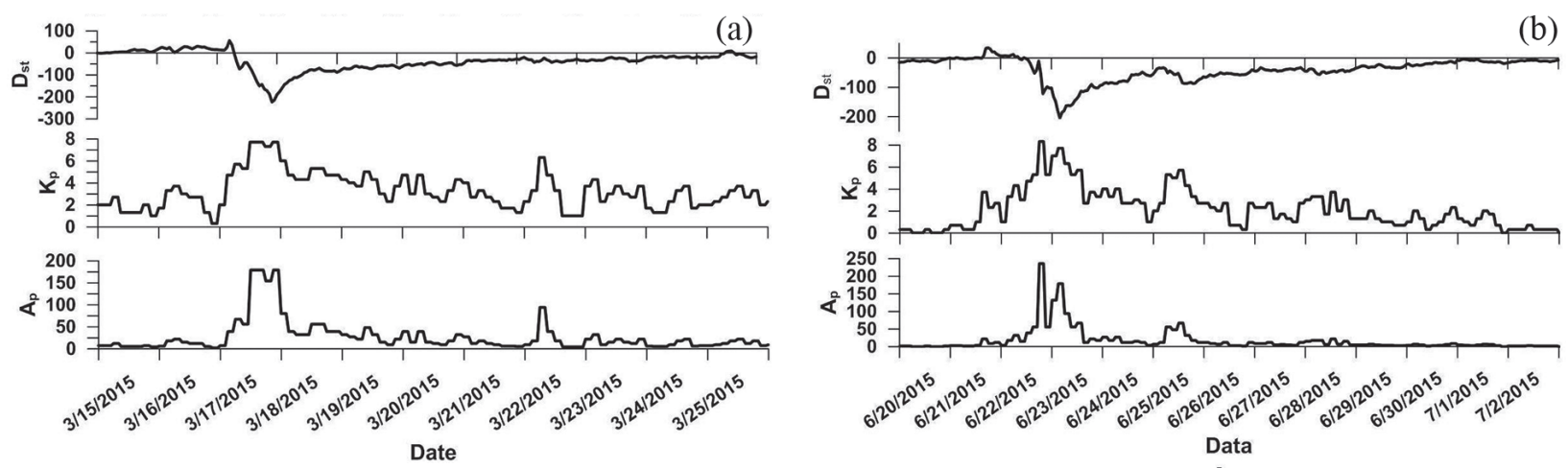

Figure 2. Time variations of the geomagnetic activity indices $D_{s t}, K_{p}$ and $A_{p}$ (http://wdc.kugi.kyoto-u.ac.jp/) during the 15-25 March 2015 storm (a), and during the 20 June- 1 July 2015 storm (b).

The figure 3 and 4 shows the global spatio-temporal variations of $v T E C$ for middle and high latitudes in the Northern Hemisphere. Dashed lines in figure 3 and 4 indicate the time of sudden storm commencement (SSC) caused by the interplanetary shock wave impact on the Earth's magnetosphere.
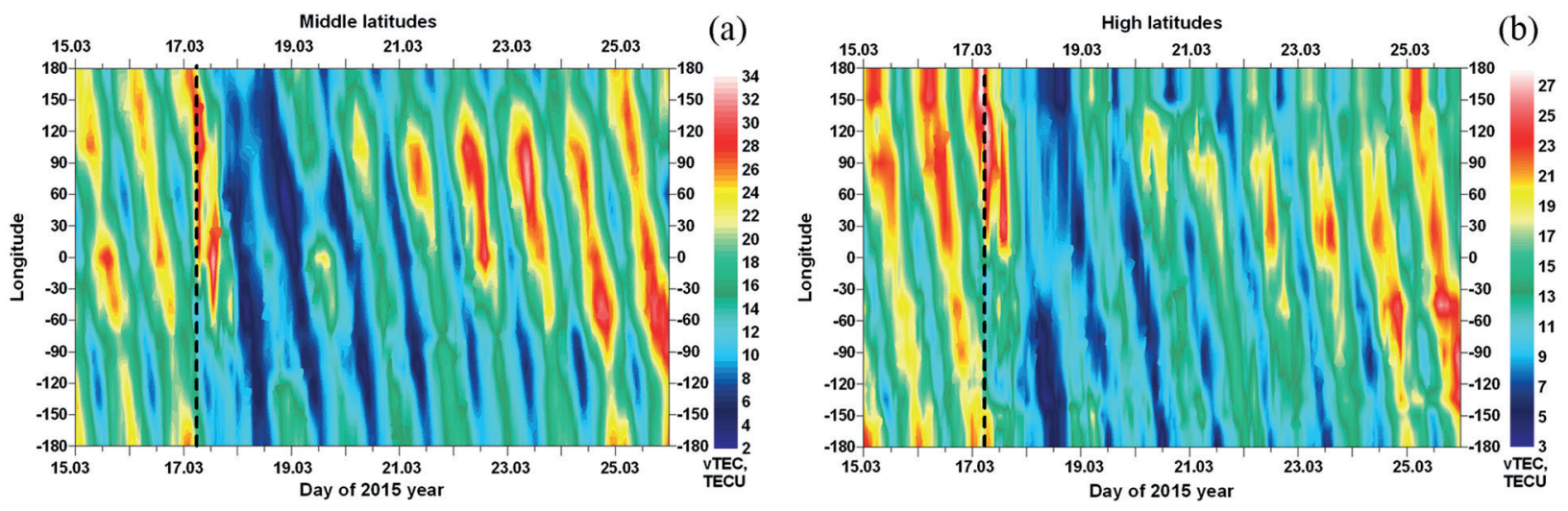

Figure 3. Longitude-time $v T E C$ variations from data of mid-latitude (a) and high-latitude (b) chains of GPS/ GLONASS receivers during the storm on March 15-25, 2015 (UT).
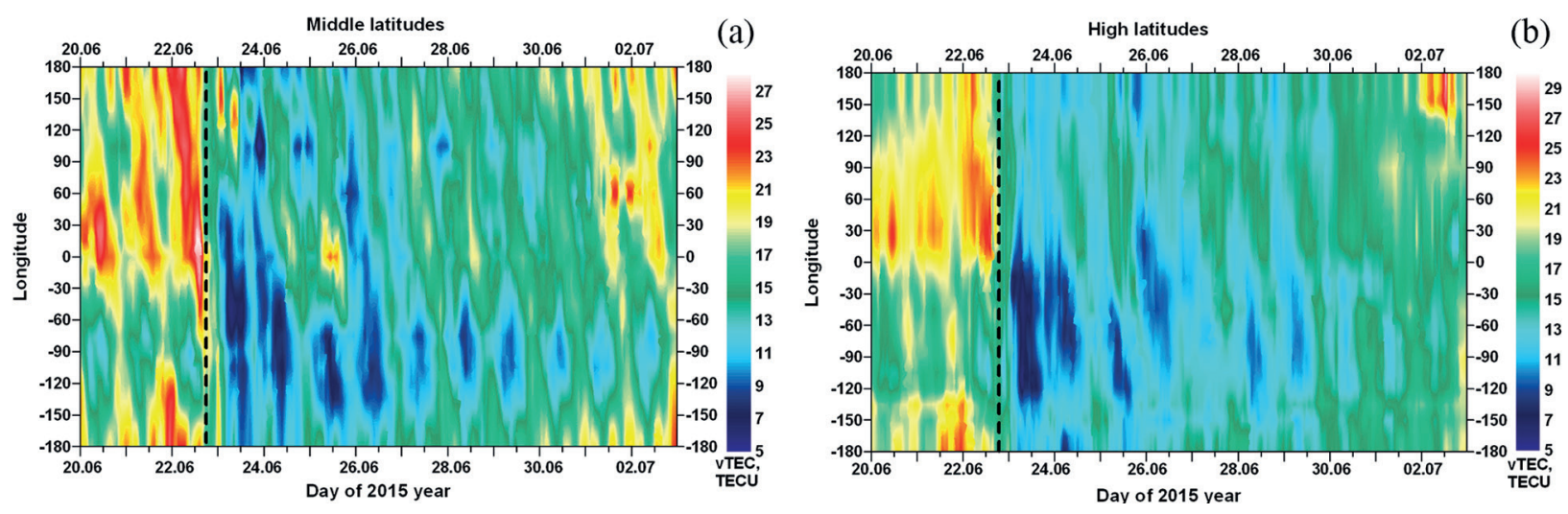

Figure 4. Longitude-time $v T E C$ variations from data of mid-latitude (a) and high-latitude (b) chains of GPS/ GLONASS receivers during the storm on June 20 - July 2, 2015 (UT).

For both severe storms in question, the total duration of ionospheric disturbance was $\sim 9$ days. The only difference of the ionospheric impact was the background ionospheric conditions. In March at the equinox, there is a marked transition from day- to night-time conditions. In June at the solstice, this transition is very weak, because at the ionospheric heights, the Sun apparently does not go down during this time. Variations of the $D_{s t}$-index (figure 2) for both storm events were almost identical, allowing one to investigate the difference between the storms in equinox and summer solstice. As we can see from variations in $K_{p}$ and $A_{p}$ indices, during the storm recovery phases, there was an additional 
sub-storm activity with $K_{p}>4$ (figure 2), which also contributed to time variations in the ionospheric ionization parameters.

It can also be noted as magnetic storminess grows, lower variability of ionization is noted at high (figure 3b, 4b) compared to middle latitudes (figure 3a, 4a). This effect has also been noted in [31].

First of all, from the maps of longitude-time $v T E C$ variations, we can note pronounced longitudinal differences in $v T E C$ variations between the Eastern and Western Hemispheres during the investigated severe storms of 2015. From the $v T E C$ distributions in figure 3 and 4 we can make a conclusion that in the Western Hemisphere over the Canadian region of the North America, the ionospheric effect of both magnetic storms is observed much longer.

It can also be noted that in the Eastern Hemisphere over the Siberian region of the Eurasia, there is a range in the interval of mid-latitudes of $\sim 80-110^{\circ} \mathrm{E}$ where the ionosphere recovers sooner after geomagnetic disturbances (figure $3 \mathrm{a}$ and $4 \mathrm{a}$ ). When discussing the ionospheric effects over Eurasia from the ionosonde chain data [26], it was emphasized that the ionosphere recovered on the 4-5th day after commencement of the March 2015 magnetic storm over the Siberian region of the Eurasia. The GPS/GLONASS dual-frequency phase receiver data generally confirm this feature for the storm in March at the equinox (figure 3).

In [26], according to the Eurasian mid-latitude ionosonde chain (figure 1b), it was established that over the Eurasian continent at longitudes $\sim 80-110^{\circ} \mathrm{E}$, the ionosphere had a positive anomaly due to low level of geomagnetic field (GMF) variations within this longitudinal sector. To study the GMF variations during the March 2015 geomagnetic storm the data of the global network of magnetometers INTERMAGNET in the Northern Hemisphere were used [26]. It should be emphasized that the geographical location of the chains of GPS/GLONASS receivers (figure 1a) is well aligned with the location of chains of the INTERMAGNET magnetometers and Eurasian ionosondes (figure 1b).

Symmetrically from the mid-latitude $\sim 80-110^{\circ}$ E sector there are two zones of increased penetration of geomagnetic disturbances from high to middle latitudes in the Eastern Hemisphere at longitudes $\sim 30-40^{\circ} \mathrm{E}, \sim 130-140^{\circ} \mathrm{E}$. In the Western Hemisphere the zones of strong variations of GMF are also formed in the direction of the geomagnetic pole meridian near the $\sim 90^{\circ} \mathrm{W}$ and at longitudes near $\sim 135^{\circ} \mathrm{W}$ and $\sim 45^{\circ} \mathrm{W}$. These zones of enhanced GMF variations correspond to the regions of strong negative ionospheric disturbances, i.e. of decreased electron density in the $F 2$ layer maximum [26] and in $v T E C$ (figure 3, 4).

Figures 3 and 4 using the GPS/GLONASS dual-frequency phase receiver data show that in the North American sector, the negative ionospheric effect of both magnetic storms is observed much longer than over the Eurasia. Negative ionospheric disturbances persist at mid-and high-latitudes for 7-8 days during the storm recovery phase for both magnetic storms. This effect is particularly pronounced in the Western Hemisphere at longitudes $\sim 50-150^{\circ} \mathrm{W}$. It should be emphasized that this longitudinal interval covers the zones of enhanced GMF variations in the Western Hemisphere during the periods of increased magnetic storminess (figure 3 and 4). Such a long-lasting and unusual effect of a magnetic storm in the ionosphere raises a natural question of the physical mechanism of the observed phenomenon.

The low electron density in the ionosphere $F$-region is formed on the Earth's night side, where conditions for westward electrojet amplification are the most favourable. In the lower thermosphere the auroral electrojet causes the gas heating. This heating is known to cause enhancement of the neutral wind velocity and higher turbulence in the lower ionosphere. This, in turn, leads to the decreased ratio $[O] /\left[N_{2}\right]$ at the heights of the upper atmosphere, and hence, to negative disturbances of electron density in the $F$-region of the ionosphere [32-37].

Earlier in the paper [26], using the Eurasian mid-latitude ionosonde chain data (figure 1b), it was shown that during the main storm phase a low ionization region (therefore, the region of the decreased ratio $[O] /\left[N_{2}\right]$ ) is formed at $\sim 130^{\circ} \mathrm{E}$ longitude in the Eastern Hemisphere over the Siberian region of the Eurasia, which moves westward from the main disturbance zone during three days at the recovery phase. This zone reached the East European sector only on March 20 [26]. Estimation of the thermosphere wind velocity gives $50-70 \mathrm{~m} / \mathrm{s}$, the reasonable value for the thermosphere. In the following days on March 21-25, during the storm recovery phase, this low electron density zone continued to move westward in the Western Hemisphere over the Canadian region of North America (figure 3a). 
To confirm the effect of the above mechanism of the geomagnetic disturbances' impact on the ionosphere, we additionally analysed data of satellite measurements of the atmosphere neutral composition obtained with UV-spectrometer GUVI TIMED at the heights of the lower thermosphere $(\sim 100 \mathrm{~km})$. Figure 5 shows satellite data on ratio $[O] /\left[N_{2}\right]$ (http://guvi.jhuapl.edu/site/data/data fetch/13_on2_gif), which confirm formation of a vast region of low ratio $[O] /\left[N_{2}\right]$ over the Far East on 17 March 2015. In the following days, the region moved westward, and reached Western Europe by $20 \mathrm{March}$. Another region of low ratio $[\mathrm{O}] /\left[\mathrm{N}_{2}\right]$, which formed over the American sector on March 17 (figure 5), has moved to $140-160^{\circ} \mathrm{E}$ by $20-21$ March 2015 , and was registered again over the Far East region.

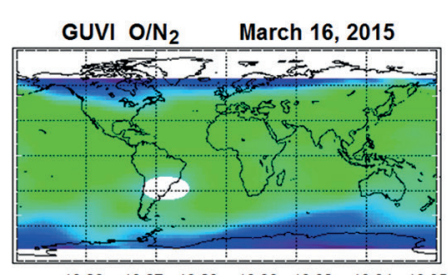

$\begin{array}{llllllll}10: 26 & 10: 27 & 10: 29 & 10: 30 & 10: 32 & 10: 34 & 10: 35 & \text { LT } \\ 18: 47 & 15: 33 & 12: 20 & 09: 06 & 05: 52 & 02: 29 & 23: 25 & \text { UT }\end{array}$

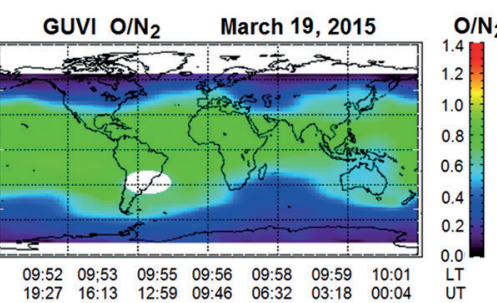

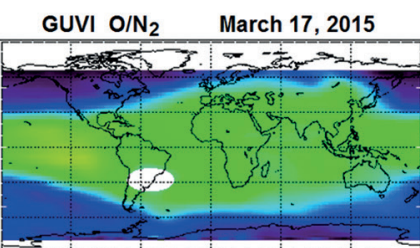

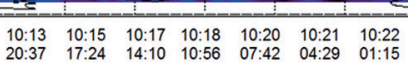

GUVI O/N2 March 20, 2015

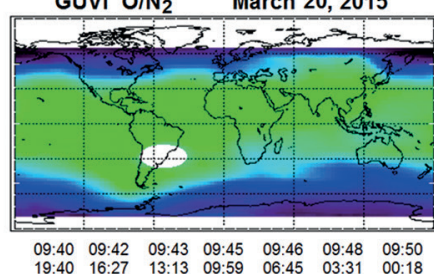

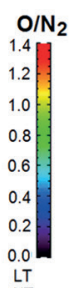

UT

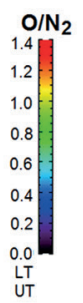

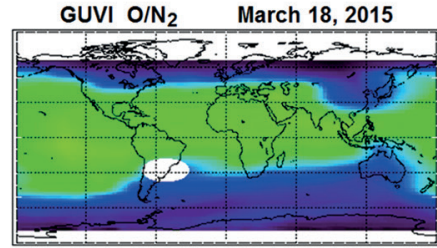

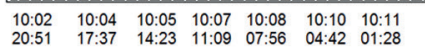

GUVI O/N 2 March 21,2015

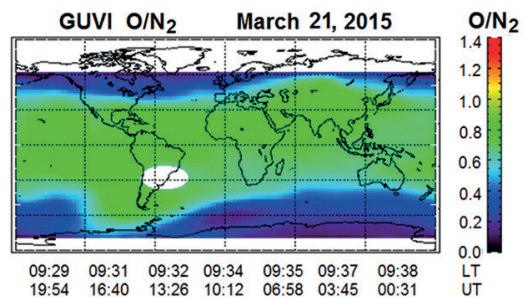

Figure 5. Ratio $[O] /\left[N_{2}\right]$ at the lower thermosphere heights according to GUVI TIMED satellite measurements on different days in March 2015.

As mentioned above, the zone of high GMF variability also existed in the North American longitudinal sector [26]. Hence, we can expect that the disturbed thermosphere zone was formed not only at $\sim 130^{\circ}$ E longitude in the Eastern Hemisphere over the Siberian region of the Eurasia but also in the Western Hemisphere over Canadian region. And this low $[O] /\left[N_{2}\right]$ zone also was moving westward during few days. Probably, the vTEC depletion at the Far East longitudes on March 20-21 (figure $3 \mathrm{~b}$ ) was the result of similar disturbed zone propagation from the North American sector, where the low $[\mathrm{O}] /\left[\mathrm{N}_{2}\right]$ zone was formed during the first impact of the main storm phase at 06:23-09:37 on March 17 (figure 2a), as it could be concluded from the GUVI data (figure 5). During this impact, the North American sector was at nighttime conditions, and development of disturbed ionosphere zone during this three-hour period was very probable.

Consequently, we focus on the pronounced, so called, after-effect of the geomagnetic disturbance on the ionosphere $[25,38]$. During the ionosphere recovery, the observed ionization was higher than on quiet days before the magnetic disturbance onset. This effect was particularly pronounced in equinox at mid-latitudes during the storm in March 2015 (figure 3a). This effect is determined by propagation of the neutral gas thermospheric wave generated in the lower thermosphere in the GMF night sector by the strong westward electrojet. Due to high frequency of collisions between molecular ions and neutrals, this wave acquires a large scale and impulse, and travels over long distances even when the magnetosphere source is "off". In this regard, one should make corrections to the traditional approach to the time interval of analysis of major geomagnetic disturbances, when the analysis ends at $D_{s t} \geqslant 0$, since perturbations in the neutral gas composition may still be in progress. If our conclusions are true, then we should say that the ionospheric effect of strong geomagnetic disturbances must be considered on a time scale for a few days after the end of the magnetic storm, while the disturbed thermosphere active zones move westward and cause the electron density decrease along the trajectories of propagation.

During the June magnetic storm at the solstice, the background density recovers quite fast due to lasting daylight in the summer ionosphere. But similar effect of moving the region of reduced electron density westward were also observed in [26] according to the Eurasian mid-latitude ionosonde chain 
because the method of vertical incidence sounding allows analyzing spatio-temporal features of the ionospheric disturbances in more detail. The method of sensing the ionosphere with GPS/GLONASS satellite signals gives the integral characteristics of the ionosphere and does not allow studying the height structure of the ionization disturbances, but enables us to effectively investigate the global features of evolution of ionospheric irregularities. However, even in the case of analysis of the integral characteristics of ionospheric ionization, one can see similar moving westward negative disturbances in Western Hemisphere (figure 4a). Unfortunately, for the period of magnetic storm in June 2015 data of satellite measurements of the atmosphere neutral composition obtained with UV-spectrometer GUVI TIMED is missing.

\section{Conclusions}

The study of ionospheric response to severe geomagnetic storms in March and June 2015 at mid- and high-latitudes of the Northern Hemisphere according to the data from two chains of GPS/GLONASS dual-frequency phase receivers allows the following conclusions.

The study of the ionospheric response to the 2015 severe geomagnetic storms showed similar scenarios of disturbances' evolution with strong dependence on the GMF parameters and the season.

During the main storm phase, the auroral precipitations are very strong in whole polar longitudinal sectors. So, the geomagnetic and ionospheric disturbances are almost synchronous at high and middle latitudes. It is associated with the global shift of the magnetosphere convection zone from high to middle latitudes.

During the recovery storm phase, the observed variations of ionospheric ionization exhibit pronounced longitudinal irregularity associated with the presence of longitudinal features background structure and variations of the main Earth's magnetic field. At that time the important role in dynamics of the mid-latitude ionosphere may also belong to disturbances in the form of thermospheric waves of molecular gas propagating westward for several days.

It is necessary to extend the time interval for studying the ionospheric effects of strong magnetic storms by a few days after the end of the magnetospheric source influence, while the disturbed thermosphere active zones continues moving westward and causes the electron density decrease along the trajectories of propagation.

\section{Acknowledgements}

This work was supported by the Russian Foundation for Basic Research Project No. 18-05-00681. The methods of software data processing were obtained with budgetary funding of Basic Research programs II.12 and II.16 (ISTP SB RAS). Experimental data were partially obtained using the equipment of Center for Common Use of scientific equipment "Angara" (ISTP SB RAS).

\section{References}

[1] Prölss G.W., Ionospheric F-region storms, Handbook of atmospheric electrodynamics, Boca Raton: CRC Press, 1995, Vol. 2, pp. 195-248.

[2] Dudok de Wit T., Watermann J., Solar forcing of the terrestrial atmosphere, Comptes Rendus Geoscience, 2009, Vol. 342(4-5), pp. 259-272.

[3] Kamide Y., Balan N., The importance of ground magnetic data in specifying the state of magnetosphere ionosphere coupling: a personal view, Geoscience Letters, 2016, Vol. 3, 10, 8 p.

[4] Buonsanto M. J., Ionospheric storms - a review, Space Science Reviews, 1999, Vol. 88, pp. 563-601.

[5] Foster J.C., Storm time plasma transport at middle and high latitudes, J. Geophysical Research, 1993, Vol. 98(A2), pp. 1675-1689.

[6] Hocke K., Schlegel K., A review of atmospheric gravity waves and traveling ionospheric disturbances: 1982-1995, Annals Geophysics, 1996, Vol. 14, pp. 917-940.

[7] Fejer B.G., Scherliess L., Mid-and low-latitude prompt-penetration ionospheric zonal plasma drifts, Geophysical Research Letters, 1998, Vol. 25, pp. 3071-3074.

[8] Fuller-Rowell T. J., Codrescu M.V., Moffett R.J., Quegan S., Response of the thermosphere and ionosphere to geomagnetic storms, J. Geophysical Research, 1994, Vol. 99(A3), pp. 3893-3914.

[9] Fuller-Rowell T.J., Codrescu M.V., Roble R.G., Richmond A. D., How Does the Thermosphere and Ionosphere React to a Geomagnetic Storm?, Magnetic storms. V. 98, 1997, Ser.: Geophysical Monograph, Washington D.C.: AGU, 1997, pp. 203-225.

[10] Lu G., Pi X., Richmond A. D., Roble R. G., Variations of total electron content during geomagnetic disturbances: A model/observation comparison, Geophysical Research Letters, 1998, Vol. 25(3), pp. 253-256. 
[11] Afraimovich E.L., Palamartchouk K.S., Perevalova N.P., GPS radio interferometry of travelling ionospheric disturbances, J. Atmospheric and Terrestrial Physics, 1998, Vol. 60(12), pp. 1205-1223.

[12] Laštovička J., Monitoring and forecasting of ionospheric space weather - Effects of geomagnetic storms, $J$. Atmospheric and Terrestrial Physics, 2002, Vol. 64, pp. 697-705, DOI: 10.1016/j.jastp.2005.01.018.

[13] Borries C., Mahrous A. M., Ellahouny N. M., Badeke R., Multiple ionospheric perturbations during the Saint Patrick's Day storm 2015 in the European-African sector, J. Geophysical Research: Space Physics, 2016, Vol. 121(11), pp. 11333-11345.

[14] Liu J., Wang W., Burns A., Yue X., Zhang S., Zhang Y., Huang C., Profiles of ionospheric storm-enhanced density during the 17 March 2015 great storm, J. Geophysical Research: Space Physics, 2015, Vol. 121(1), pp. $727-744$.

[15] Liu Y., Fu L., Wang J., Zhang C., Studying Ionosphere Responses to a Geomagnetic Storm in June 2015 with Multi-Constellation Observations, Remote Sensing, 2018, Vol. 10, pp. 666-686, DOI: 10.3390/rs10050666.

[16] Verkhoglyadova O.P., Tsurutani B.T., Mannucci A.J., Mlynczak M. G., Hunt L.A., Paxton L.J., Komjathy A.J., Solar wind driving of ionosphere-thermosphere responses in three storms near St. Patrick's Day in 2012, 2013, and 2015., J. Geophysical Research: Space Physics, 2016, Vol. 121(9), pp. 8900-8923.

[17] Astafyeva E., Zakharenkova I., Förster M.J., Ionospheric response to the 2015 St. Patrick's Day storm: A global multi-instrumental overview, J. Geophysical Research: Space Physics, 2015, Vol. 120(10), pp. 9023-9037, DOI: 10.1002/2015JA021629.

[18] Astafyeva E., Zakharenkova I., Huba J.D., Doornbos E., van den Ijssel J., Global Ionospheric and thermospheric effects of the June 2015 geomagnetic disturbances: Multi-instrumental observations and modelling, J. Geophysical Research: Space Physics, 2017, Vol. 122(11), pp. 11716-11742, DOI: 10.1002/2017JA024174.

[19] Astafyeva E., Zakharenkova I., Hozumi K., Alken P., Coïsson P., Hairston M. R., Coley W. R., Study of the Equatorial and Low-latitude Electrodynamic and Ionospheric Disturbances during the 22-23 June 2015 Geomagnetic Storm Using Ground-based and Space-borne Techniques, J. Geophysical Research: Space Physics, 2018, Vol. 123(3), pp. 2424-2440, DOI: 10.1002/2017JA024981.

[20] Kunitsyn V. E., Padokhin A. M., Kurbatov G.A., Yasyukevich Yu. V., Morozov Yu. V., Ionospheric TEC estimation with the signals of various geostationary navigational satellites, GPS Solutions, 2016, Vol. 20(4), pp. 877-884, DOI: 10.1007/s10291-015-0500-2.

[21] Wu C. C., Liou K., Lepping R. P., Hutting L., Plunkett S., Howard R.A., Socker D., The first super geomagnetic storm of solar cycle 24: "The St. Patrick's Day event (17 March 2015)", Earth Planets Space, 2016, Vol. 68, pp. 151-162, DOI: 10.1186/s40623-016-0525-y.

[22] Zakharenkova I., Astafyeva E. Cherniak I., GPS and GLONASS observations of traveling ionospheric disturbances during the 2015 St. Patrick's Day storm, J. Geophysical Research: Space Physics, 2016, Vol. 121(12), pp. 12138-12156, DOI: 10.1002/2016JA023332.

[23] Zakharenkova I.E., Cherniak Iu. V., Shagimuratov I. I., Klimenko M.V., Features of High-Latitude Ionospheric Irregularities Development as Revealed by Ground-Based GPS Observations, SatelliteBorne GPS Observations and Satellite in situ Measurements over the Territory of Russia during the Geomagnetic Storm on March 17-18, 2015, Geomagnetism and Aeronomy, 2018, Vol. 58(1), pp. 70-82.

[24] Zolotukhina N., Polekh N., Kurkin V., Rogov D., Romanova E., Elpanov M., Ionospheric effects of St. Patrick's storm over Asian Russia: 17-19 March 2015, J. Geophysical Research: Space Physics, 2017, Vol. 122(2), pp. 2484-2504.

[25] Klimenko M.V., Klimenko V.V., Despirak I.V., Zakharenkova I.E., Kozelov B.V., Cherniakov S. M., Andreeva E. S., Tereshchenko E. D., Vesnin A. M., Korenkova N.A., Gomonov A. D., Vasiliev E. B., Ratovsky K. G., Disturbances of the thermosphere-ionosphere-plasmasphere system including auroral electrojet at $30^{\circ}$ E longitude during the St. Patrick's Day Geomagnetic Storm on March 17-23, 2015, J. Atmospheric and Solar-Terrestrial Physics, 2018, Vol. 180, pp. 78-92.

[26] Shpynev B. G., Zolotukhina N.A., Polekh N. M., Ratovsky K. G., Chernigovskaya M.A., Belinskaya A. Yu., Stepanov A. E., Bychkov V. V., Grigorieva S. A., Panchenko V. A., Korenkova N.A., Mielich J., The ionosphere response to severe geomagnetic storm in March 2015 on the base of the data from Eurasian high-middle latitudes ionosonde chain, J. Atmospheric and Solar-Terrestrial Physics, 2018, Vol. 180, pp. 93-105.

[27] Polekh N. M., Zolotukhina N.A., Romanova E. B., Ponomarchuk S. N., Urkin V. I., Podlesnyi A. V., Ionospheric effects of magnetospheric and thermospheric disturbances on March 17-19, 2015, Geomagnetism and Aeronomy, 2016, Vol. 56(5), pp. 557-571.

[28] Nayak C., Tsai L.-C., Su S.-Y., Galkin I.A., Tan A.T. K., Nofri E., Jamjareegulgarn P., Peculiar features of the low-latitude and midlatitude ionospheric response to the St. Patrick's Day geomagnetic storm of 17 March 2015, J. Geophysical Research: Space Physics, 2016, Vol. 121(8), pp. 7941-7960.

[29] Yasyukevich Yu. V., Mylnikova A. A., Polyakova A. S., Estimating the total electron content absolute value from the GPS/GLONASS data, Results Physics, 2015, Vol. 5, pp. 32-33. 
[30] Loewe C.A., Prölss G.W., Classification and mean behavior of magnetic storms, J. Geophysical Research, 1997, Vol. 102(A7), pp. 14209-14213.

[31] Araujo-Pradere E.A., Fuller-Rowell T.J., Codrescu M.V., Bilitza D., Characteristics of the ionospheric variability as a function of season, latitude, local time, and geomagnetic activity, Radio Science, 2005, Vol. 40, RS5009, 16 p.

[32] Rishbeth H., Müller-Wodarg I.C.F., Vertical circulation and thermospheric composition: A modelling study, Annals Geophysics, 1999, Vol. 17(6), pp. 794-805.

[33] Prölss G.W., Werner S., Vibrationally excited nitrogen and oxygen and the origin of negative ionospheric storms, J. Geophysical Research, 2002, Vol. 107(A2), 1016, 6 p., DOI: 10.1029/2001JA900126.

[34] Danilov A. D., Long-term trends of foF2 independent on geomagnetic activity, Annals Geophysics, 2003, Vol. 21(5), pp. 1167-1176.

[35] Liou K., Newell P. T., Anderson B.J., Zanetti L., Meng C.-I., Neutral composition effects on ionospheric storms at middle and low latitudes., J. Geophysical Research, 2005, Vol. 110(A5), A05309, 12 p., DOI: 10.1029/2004JA010840.

[36] Laštovička J., Forcing of the ionosphere by waves from below, J. Atmospheric and Solar-Terrestrial Physics, 2006, Vol. 68(3-5), pp. 479-497.

[37] Klimenko M. V., Klimenko V.V., Ratovsky K. G., Goncharenko L.P., Fagundes R. R., de Jesus R., de Abreu A. J., Vesnin A. M., Numerical modelling of ionospheric effects in the middle- and low-latitude F region during geomagnetic storm sequence of 9-14 September 2005, Radio Science, 2011, Vol. 46(3), RS0D03, 18 p., DOI: 10.1029/2010RS004590.

[38] Ratovsky K. G., Klimenko M.V., Klimenko V.V., Chirik N. V., Korenkova N.A., Kotova D.S., Aftereffects of geomagnetic storms: statistical analysis and theoretical explanation, J. Solar-Terrestrial Physics, 2018, Vol. 4(4), pp. 26-32, DOI: 10.12737/stp-44201804. 